\title{
Analysis of a solar dish-Stirling system with hybridization and thermal storage
}

\author{
Carlos Monné • Yolanda Bravo • Francisco Moreno • \\ Mariano Muñoz
}

Received: 21 June 2013/Accepted: 29 November 2013/Published online: 1 April 2014

(C) The Author(s) 2014. This article is published with open access at Springerlink.com

\begin{abstract}
A high potential of thermosolar power generation systems is the use of thermal storage and/or hybridization to overcome dependability of solar resource availability. The incorporation of these technologies can be of special interest for isolated units intended for distributed generation systems. Among the thermosolar systems, dishStirling technology is the one with more possibilities to be used as a system to feed power independently, i.e., due to the modularity of the units that range between 3 and $25 \mathrm{kWe}$, depending on the supplier. Thus, the present analysis is focused on studying integration of both hybridization and thermal storage in an isolated unit of $10 \mathrm{kWe}$ dish-Stirling. In particular, hybridization will enable a more continuous operation of the system. Hybridization is analyzed both for a conventional fuel, such as natural gas, and for a renewable energy source, biogas. Analysis of performance of the dish-Stirling system enables to determine the interest of introducing the complementary technologies referred above. Regarding the specific case evaluated in this paper, analyzed data show that hybridization has an advantage that depends on the
\end{abstract}

5th International Congress on Energy and Environmental Engineering and Management (CIIEM).

C. Monné · Y. Bravo $(\bowtie) \cdot$ F. Moreno · M. Muñoz

Department of Mechanical Engineering, Aragon Institute of

Engineering Research (I3A), University of Zaragoza, C/Mariano

Esquillor s/n, 50018 Saragossa, Spain

e-mail: ybravo@unizar.es

C. Monné

e-mail: cmmb@unizar.es

F. Moreno

e-mail: fmoreno@unizar.es

M. Muñoz

e-mail:mmunoz@unizar.es nature of fuel used, being of $20 \%$ for natural gas and $112 \%$ for biogas in relation to output power of solar-only operation. Thermal energy storage system shows no significant benefits when implemented to a variable power system.

Keywords Dish-Stirling system - Hybridization · Thermal energy storage · Productivity improvement · CSP
Abbreviation
DNI Direct normal irradiation

\section{Introduction}

High concentration solar thermal technologies use concentrated solar power to convert the radiation into mechanical energy through a thermodynamic cycle, and then converting it to electricity. Most known technologies are parabolic trough and central receiver. Dish-Stirling systems are the third thermosolar system, which is in first phase of industrialization. These systems use mirrors disposed on a parabolic surface to focus solar radiator onto a receiver. This receiver transfers the energy to a Stirling engine. Main advantages of dish-Stirling systems are modularity, with units varying from 3 to $25 \mathrm{kWe}$, and high efficiency. In fact, it has shown the greatest energy conversion coefficient among all the solar technologies, $29.4 \%[1,2]$, and therefore, this technology owns a big potential in relation to other sources of green electricity. What is more, its modularity allows to operate individually (remote locations), or to be associated with several dishStirling systems to operate in small groups and be connected to the electrical grid (village power). The main components of a dish-Stirling system (Fig. 1) are: 


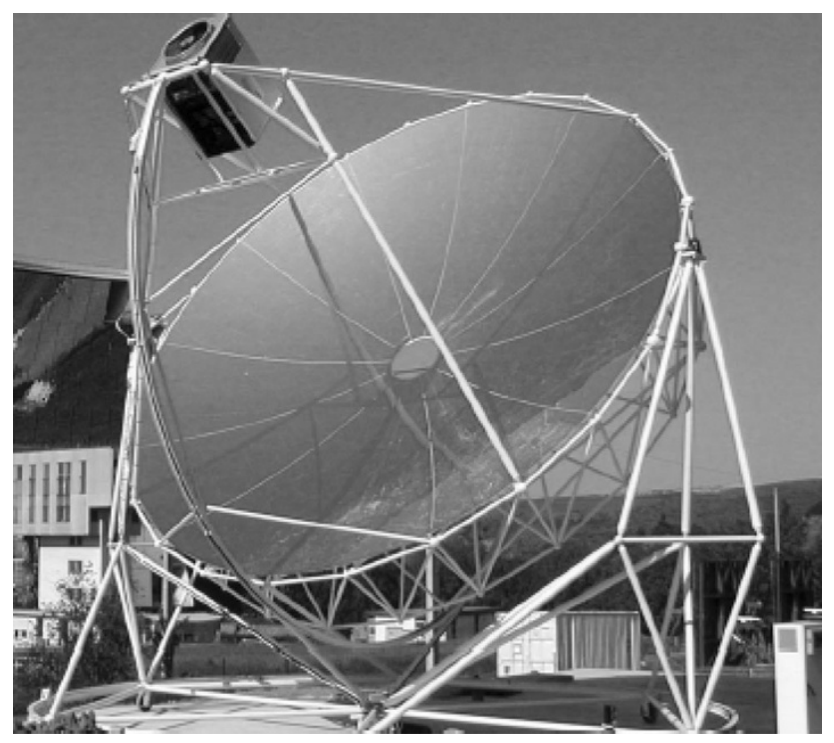

Fig. 1 Dish-Stirling system

concentrator shell, receiver, Stirling engine, tracking system, cooling system, and structural framework.

One of the drawbacks of the use of this technology is that it depends on solar source availability, i.e., why the incorporation of both thermal storage and hybridization could overcome this issue, since it provides the possibility to have more operating hours and flexibility. There is a variety of projects in relation to definition of components that should be used for hybridization, mainly the receiver to be capable to cope with solar and auxiliary energy [3]. However, also the evaluation of how these two techniques can be applied must be analyzed to evaluate the operational advantage. It can help to drive further developments.

\section{Methods}

For this analysis, specific software developed by Zaragoza University has been used, named DNIcal [1, 4, 5]. This software takes the direct normal irradiation (DNI) during a period of time and by implementation of the dish-Stirling model, the result is given in terms of electricity produced. The model of the system corresponds to the $10 \mathrm{~kW} \mathrm{SBP}$ system [6]. Model of the system consists of definition of efficiencies of the different components [7]. These efficiencies are taken both from experimental [8] and modellization previous studies [9]. In relation to previous references, the main advantage of this software is that it includes the possibility to add both thermal storage and hybridization to the dish-Stirling system [10]. Thus, in addition to the analysis of the system, it includes an analysis of energy received, considering periods where auxiliary energy can be implemented. It takes into account the periods where direct irradiation is under nominal performance value of the system, such as first and last hours of the day, together with phenomena such as clouding that imply a temporary decrease in the solar energy received. As for thermal storage application, it considers also periods where solar irradiation is above the nominal value, to calculate excess energy that can be used in transient periods. The energy that can be provided by the auxiliary systems is also included in modellization. As for hybridization, it must be included the maximum percentage that is allowed to be covered by this system (based on national regulation [11]). Regarding thermal storage, the capacity of the system must be defined. For this issue, the limitation in weight of this system must be considered, given the fact that the system would be mounted on moving structure of the system.

Basically, the model can be summarized in the following steps. Solar energy radiation is collected by the parabolic dish that transfers it to the concentrator, then this element concentrates the solar power on the receiver that has losses associated to interception and reflectivity. The inlet power for the engine from the receiver must take into account thermal losses. Finally, electric power that is obtained from the Stirling engine is determined by the efficiency of the engine itself.

Inlet data for the software concerning the system definition are listed below:

- Nominal irradiance value for the system.

- Decrease of irradiance and duration to consider a transient period.

- Maximum percentage of electricity demand that can be covered by hybridization.

- System efficiency operating with combustion.

- Cost of kWh for the fuel used for hybridization.

- Maximum amount of energy for the thermal storage system.

The inlet data for meteorological characterization determine the supplied energy to the facility. These data are associated to a specific geographic location during a period of time. The values of direct solar energy are collected with a temporary frequency that enables to define the radiation curve along the day. The meteorological data are defined in a yearly basis. Thus, the analysis can be made by day, month and year. In the case of analysis, the data for several years have been taken to calculate the results for an average year, giving the results in a yearly basis.

The parameters for analysis correspond to the response of the system for electricity generation. These parameters are related to technical and economical feasibility of the different alternatives analyzed. The comparison will enable to determine if hybridization or thermal storage presents an advantage for the operation of the system. The parameters are the following: 
- Output power. The software enables to calculate output power during a selected period of time with given meteorological data.

- Equivalent operation hours, calculated on the basis of nominal operation.

- Capacity of the facility. It is calculated as the calculated output power during a period of time in relation to the nominal operation with the system operating the whole day.

\section{Results and discussion}

The operation just with solar energy is the reference to determine the gain of using the systems of hybridization and thermal storage. The software enables to select two different operation modes: constant power and variable power. The first one occurs when the system is active only when the solar radiation attains the nominal value. The second one occurs when the system adapts its operation to the radiation received. If both modes are considered for a mean year at the location of Sevilla, the following values are obtained for power output: 4,675 kWh for constant power and $16,407 \mathrm{kWh}$ for variable power. This significant difference points out the need of defining a system that enables to operate with variable power. Thus, the following analysis will be based on the assumption of a system with variable power.

As for variable power, it is also interesting to evaluate the difference on output power per month. The electricity produced from April to September represents the $65 \%$ of the total output. By month, the month of July presents the highest value of output with $2,265 \mathrm{kWh}$ in relation to December, with the lowest value, i.e., $562 \mathrm{kWh}$.

In general, the application of hybridization provides flexibility, adaptation to meteorological transient period and improvement of the power management. What is more, it enables to improve investment recovery and operation time. As the Stirling engine is an external combustion engine, it can be supplied with different energy sources. The application of hybridization can mean the use of these alternative energy sources combined or alternatively with solar operation. The hybridization with fossil fuels means by adding a combustion system to the facility is a feasible alternative due to the availability of this type of fuels. It is especially interesting if it is considered that areas where this technology could have a higher potential of implementation (for example, North Africa or Medium Orient) can be also producers of fossil fuels. In particular, for this study natural gas has been considered. Figure 2 shows an example for a representative day for potential use of hybridization and thermal storage.

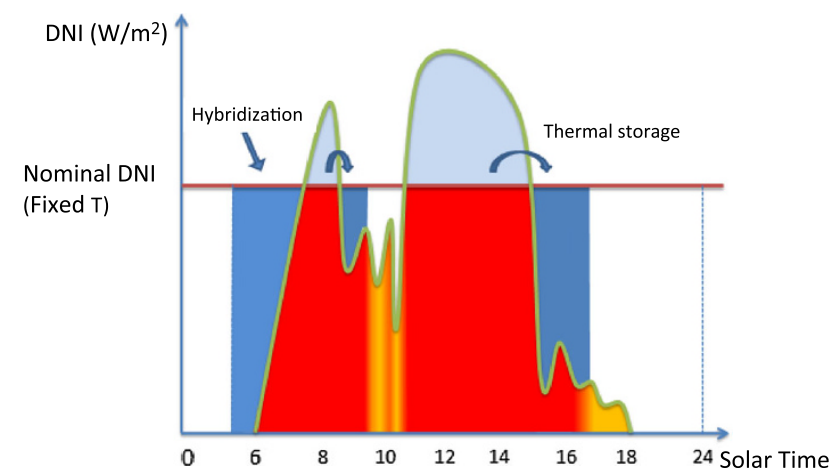

Fig. 2 Application of hybridization and thermal storage to solar-only operation

The hybridization can be limited by national regulations. The limit depends on the nature of the fuel used for the hybridization. In the case of Spain, the RD661/2007 [11] establishes a limit of $12 \%$ of the annual electricity generated for fossil fuels, with the exception of natural gas that increases up to $15 \%$. The limitation in Spain has been imposed trying to be representative of the potential of the facility also in other regions that establish similar limits for hybridization [12, 13].

The application of hybridization with natural gas will be made mainly in first hours of the day, when demand is higher. The modellization of the hybridized system with natural gas results in an annual production of 19,804 kWh.

The hybridization with fossil fuels means the combination of a renewable source, i.e., the solar one, with a non renewable source. As an alternative to that, it is also possible to use biogas as fuel for energy supply through combustion. Thus, it represents a lower environmental impact. In addition to that, it is especially interesting for isolated units where the supply of natural gas can be not feasible. The limitation imposed by Spanish regulation [11] is significantly higher than for natural gas. The limit is established in $50 \%$ of supply with biogas hybridization in relation to annual electricity generation. That is, $50 \%$ of the total output of the hybridized facility can be provided by the biogas combustion. The annual production calculated with the application of the software results in a value of $34,779 \mathrm{kWh}$.

Other parameters that are used for evaluation of hybridization gain are [14]:

- Equivalent operating hours. As previously indicated, the increase in equivalent operating hours is limited by power facility regulation in relation to hybridization. In relation to operation with only solar resource, the hybridization with natural gas results in a gain of $20 \%$ of electricity production. In the case of biogas, this increase goes up to $112 \%$. It must be explained that an increase higher than $100 \%$ associated to the maximum 


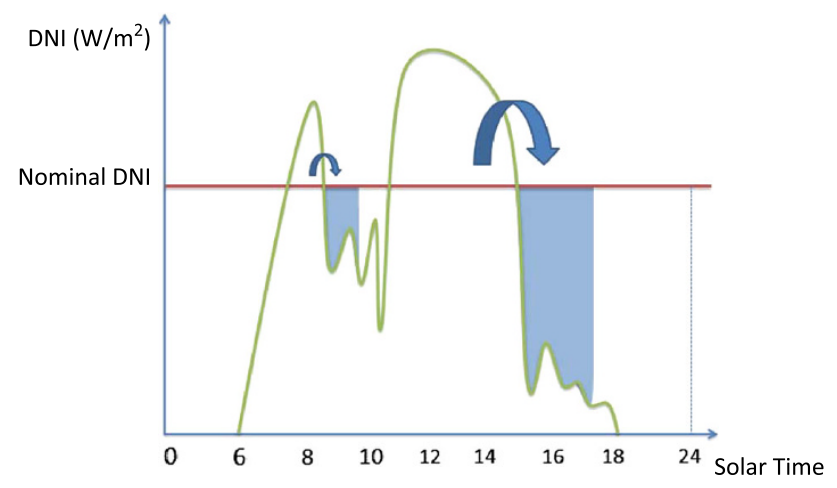

Fig. 3 Maximum energy supply for a thermal storage system

rate of hybridization of $50 \%$ is possible because the facility changes operation point varying overall efficiency, i.e., application of hybridization means not only a gain by adding an additional energy source supply, but also because the facility works in a more efficient condition. Translation of this increase into equivalent operation hours results in estimation of $6.0 \mathrm{~h}$ for application of natural gas and $10.5 \mathrm{~h}$ for biogas in comparison with the average use of $4.9 \mathrm{~h}$ with the facility operating just with solar resource.

- Capacity factor. This parameter is taken as the simulated output electricity compared with the ideal output if it could be operated the entire day at full-load capacity (in the case that no restrictions would be applied for hybridization). Capacity factor for the natural gas hybrid system is $23 \%$, and for the biogas hybrid system $40 \%$, compared with solar-only operation value of $19 \%$.

Thermal storage can be also used as auxiliary energy to provide more continuous operation of the facility. The energy is stored during the period where the solar radiation value exceeds the nominal value of the system, in such a way that this energy is released in the periods where the energy can be needed, such as transients. It is assumed a limit in storage capacity of $50 \mathrm{Wh} / \mathrm{m}^{2}$ [15] and that all energy stored will be used during the daily operation. Of course, the thermal storage system will not be able to ensure full continuous operation along the day, due to its intrinsic storage capacity. The energy provided by the thermal storage system will be normally provided during the last hours of the day or in the periods where solar radiation falls due to cloudy weather. In the dishStirling system analyzed, with a nominal value of radiation of $800 \mathrm{~W} / \mathrm{m}^{2}$, working on a variable power basis, the potential of recuperated energy through thermal storage is very low. Figure 3 illustrates an example for a typical day with the periods of excess of energy and application of recuperation. In relation to the value of $16,407 \mathrm{kWh}$ of output power, it just adds $10 \mathrm{kWh}$ during an average year.
It is considered that the thermal storage system could be interesting only for the following cases: system working at constant power or a system with nominal power lower than $10 \mathrm{~kW}$. However, the benefits of implementing such a system must be balanced with costs associated to its use.

\section{Conclusions}

The application of developed software has enabled to evaluate the implementation of two different auxiliary energy supply systems: thermal storage and hybridization. In principal, the two systems can be used to increase the electricity output for the dish-Stirling technology. The software inputs are parameters for definition of the dishStirling facility and solar irradiance data for a specific location. Analysis of solar-only operation shows the advantage of variable power facilities that take profit of the incident radiation even if it does not attain nominal value of the system.

Hybridization shows a clear benefit regarding operational parameters of the system. The fuel used for this hybridization determines the limits associated to a specific national regulation, and therefore the gains. This regulation establishes a higher limit in case of renewable source, i.e., biogas, than for conventional fuels, such as natural gas. The output power increases in $112 \%$ for biogas and $20 \%$ for natural gas in relation to solar-only operation. The gain in operating hours in relation to $4.9 \mathrm{~h}$ for variable power system with solar energy is 10.5 for biogas and 6.0 for natural gas. Also capacity factor increases from 19 to $40 \%$ for biogas and $23 \%$ for natural gas.

As for thermal storage, it shows no clear benefit when variable power system is used.

Conflict of interest The authors declare that they have no competing interest.

Author's contributions CM developed the software used for the analysis. YB applied the software to a specific facility and made the analysis of results. FM conceived the study and participated in coordination. MM participated in the coordination and review of the article.

Author's information All the authors are professors at Zaragoza University in the Mechanical Engineering Department, at knowledge area of Thermal Engines and Machines. FM and MM are engine experts and lead the Thermal Engines Laboratory. CM is specialized in Renewable Energies and Efficiency Optimization. YB is an Associate Professor, and is now developing the $\mathrm{PhD}$ in the field of dish Stirling technology.

Open Access This article is distributed under the terms of the Creative Commons Attribution License which permits any use, distribution, and reproduction in any medium, provided the original author(s) and the source are credited. 


\section{References}

1. Droher, J., Squier, S.: Performance of the Vanguard solar dishStirling module. Electric Power Research, Institute Palo Alto Report (1990)

2. Stine, W.B., Diver, R.P.: A compendium of solar dish-Stirling technology. Sandia National Laboratories Report (1994)

3. Monné, C., Bravo, Y., Alonso, S., Moreno, F., Muñoz, M.: Developments for future implementation in dish-Stirling technology. Strojarstvo 55(1), 35-44 (2013)

4. Quintana, J.L., Monné, C.: Análisis del potencial de aplicación de nuevas tecnologías en sistemas de captación solar térmica. Proyecto Fin de Carrera/Universidad de, Zaragoza (2011)

5. Ara, C., Monné, C.: Análisis de viabilidad de tecnologías de apoyo energético para sistemas de disco Stirling. Proyecto Fin de Carrera/Universidad de, Zaragoza (2011)

6. Bravo, Y.: Dish-Stirling generation systems: State of art review and Life Cycle Analysis (Sistemas de generación tecnología disco-Stirling: revisión de estado del arte y análisis de ciclo de vida). $6^{\circ}$ Workshop de Tecnologías de Climatización y Eficiencia Energética en Edificios. E.T.S.I.Q. Tarragona. (2010) (In Spanish)

7. Bravo, Y., Carvalho, M., Serra, L.M., Monné, C., Alonso, S., Moreno, F., Muñoz, M.: Environmental evaluation of dish-
Stirling technology for power generation. Solar Energy 86(9), 2811-2825 (2012). ISSN 0038-092X

8. Reinalter, W., Ulmer, S., Heller, P., Rauch, T., Gineste, J.-M., Ferriere, A., Nepveu, F.: Detailed performance analysis of the 10-kW CNRS-PROMES dish/Stirling system. SolarPACES2006 A7-S7 (2006)

9. Fraser, P.: Stirling dish system performance prediction model. Thesis submitted to University of Wisconsin-Madison (2008)

10. Bravo, Y., Monné, C., Moreno, F.: Beneficios de la hibridación CSP-Biogas. Perspectivas de utilización. ERA SOLAR. 173, 36-43 (2013). ISSN 0212-4157. (In Spanish)

11. BOE 2007/Real Decreto 661/2007, BOE 25 mayo 2007 (Spain Government Communications)

12. Geyer, A., Holländer, A., Aringhoff, R., Nava, P.: Hälfte des weltweit produzierten Solarstroms. Sonnenenergie (1998)

13. Mohr, M., Svoboda, P., Unger, H.: Praxis solarthermischer Kraftwerke. Springer, Berlin (1999)

14. Barea, J.M., Ordoñez, I., Silva, M.: Energy analysis of parabolic trough solar power station with and without biomass hybridization. SolarPaces, pp. 40206 (2012)

15. PCM Products Ltd. Product catalogue. Encapsulated solutions. http://www.pcmproducts.net/ (2009) 